\title{
Robot-assisted navigation system for CT-guided percutaneous lung tumour procedures: our initial experience in Hong Kong
}

\author{
CM Chu*, SCH Yu \\ From International Cancer Imaging Society (ICIS) 14th Annual Teaching Course \\ Heidelberg, Germany. 9-11 October 2014
}

\section{Purpose}

To evaluate the new robot-assisted navigation system for CT-guided lung tumour procedures

\section{Materials and methods}

Imaging-guided lung procedures are usually challenging due to patient breathing. This is an ongoing prospective study with 50 patients targeted in a university-based hospital. This was an initial assessment of efficacy involving 10 patients with lung tumours who underwent CT-guided lung interventions utilizing the robot-assisted Navigation system (Maxio, Perfint Healthcare, USA). The targeted needle pathway was planned on Maxio Robotic system based on pre-procedural CT-scans. The primary endpoint was satisfactory instrument position for intended intervention. Lesion size and depth from skin were noted. Performance level was documented on a five-point scale (5-1: excellent-poor). Total radiation doses were recorded and compared against 20 patients with conventional CTguidance and CT-fluoroscopy lung procedures (ratio 1:1). was 645.4 (range 285.1-1043.5) and CT-fluoroscopy was 460.1 (range 214.2-1157.0).

\section{Conclusions}

Our initial experience demonstrated effectiveness of the robot-assisted navigation system for CT-guided lung tumour interventions with lower radiation dose compared with conventional CT-guided procedures. Radiation doses were similar to CT-fluoroscopy without radiation exposure to interventional radiologists. Targeting success rate for satisfactory intervention was $100 \%$.

Published: 9 October 2014

doi:10.1186/1470-7330-14-S1-S5

Cite this article as: Chu and Yu: Robot-assisted navigation system for CT-guided percutaneous lung tumour procedures: our initial experience in Hong Kong. Cancer Imaging 2014 14(Suppl 1):S5.

\section{Results}

There were 7 male and 3 female patients in the robotic group. Average age was 72.1 years (range 67-78). 8 patients underwent lung biopsy while the rest had thermal ablation or fiducial marker insertion. Average lesion size was $2.8 \mathrm{~cm}$ (range 1.9-4.1cm). Average lesion depth was $6.2 \mathrm{~cm}$ (range $3.7-8.6 \mathrm{~cm}$ ). All interventions met the primary endpoint of satisfactory instrument positioning. Average performance levels were 4.5. Average radiation dose (Dose Linear Product) was 480.4 (range 196.5-959.8) whereas conventional CT-guidance

\footnotetext{
* Correspondence: charmantchu@gmail.com

Department of Imaging and Interventional Radiology The Chinese University of Hong Kong, Prince of Wales Hospital, Shatin, N.T., Hong Kong
}

Submit your next manuscript to BioMed Central and take full advantage of:

- Convenient online submission

- Thorough peer review

- No space constraints or color figure charges

- Immediate publication on acceptance

- Inclusion in PubMed, CAS, Scopus and Google Scholar

- Research which is freely available for redistribution 